\title{
Arquitectura visionaria: la utopía dibujada
}

\author{
Visionary architecture: the drawn utopia
}

\section{Resumen}

Pontificia Universidad Católica del Ecuador (PUCE)

Ecuador
D urante la llustración, Boullée ya criticaba la visión vitruviana de ver a la arquitectura como el arte de construir. Para él existía un paso previo: antes de construir hay que concebir. La creación arquitectónica es la consecuencia de una crítica poética o proyectual. Así, la meta de la crítica siempre es la propuesta de nuevas ideas. De dicha manera evoluciona la disciplina. Las ideas son representadas a través de la utopía, y estas son las que cambian al mundo y no la limitada y dogmática realidad. Miremos los «Disparates» de Goya, o la realidad esencial no figurativa que nos querían trasmitir los artistas del Cubismo. El dibujo es un medio para expresar ideas muy sugerentes que pueden llevar a la arquitectura a un estado filosófico y teórico más propositivo. Ejemplo de ello han sido Piranesi con sus «Cárceles», Boullée con su "Cenotafio de Newton», Sant'Elia con su « Città Nuova», Chernikov con sus «Architectural fantasies». Sin dejar de nombrar a Taut, Archigram o Woods. Son todos ellos grandes visionarios que no necesitaron construir para dar grandes aportes a la arquitectura. Ellos necesitaron concebir y su medio fue el dibujo. Un dibujo puede explicar toda una filosofía de pensamiento en muy pocos trazos.

Palabras clave: Arquitectura, utopía, dibujo, imaginación, idea, concepción.

\section{Abstract:}

During the Age of Reason, Boullée already criticized the Vitruvian vision of seeing architecture as the art of building. For him there was a previous step: before constructing it is necessary to conceive. The architectural creation is the consequence of a poetic or projectual criticism. Thus, the goal of criticism is always the proposal of new ideas. In this way the discipline evolves. Ideas are represented through utopia, and it is which change the world, not the limited and dogmatic reality. Let's look at the "Disparates" of Goya, or the essential non-figurative reality that Cubist artists wanted to convey to us. The drawing is a means to express very suggestive ideas that can take to the architecture to a more propitious philosophical and theoretical state. Examples of this were Piranesi with his "Prisons", Boullée with his "Newton's Cenotaph ", Sant'Elia with his "Città Nuova", Chernikov with his "Architectural fantasies". Without forgetting Taut, Archigram or Woods. They are all great visionaries who did not need to build to give great contributions to architecture. They needed to conceive and their medium was drawing. A drawing can explain a whole philosophy of thought in very few strokes

Keywords: Architecture, utopia, drawing, imagination, idea, conception. 


\section{Introducción}

Másque una descripción panorámica de arquitectos visionarios, la presente reflexión busca reivindicar la importancia de la arquitectura imaginada. Defender tanto la concepción arquitectónica previa a la construcción como la poética previa a la técnica. Obviamente se apuntala a este escrito a través de la mirada de ciertos personajes notables dentro de la arquitectura visionaria, y cómo el dibujo es el medio conmensurable que materializa lo inconmensurable. El dibujo es la herramienta que nos traduce la idea en hecho. Así, el problema nos plantea las siguientes preguntas: ¿Una obra arquitectónica debe estar construida físicamente para estar realizada? ¿Si no tenemos la oportunidad de construir, podemos ejercer el oficio? El poeta estadounidense Walt Whitman decía: "The greatest poet is not the one who wrote best but the one who suggested most"1 ${ }^{1}$. Como una apología a esta frase, podemos redefinir qué es arquitectura. La arquitectura se manifiesta como una ofrenda del espíritu humano. No es mejor arquitecto el que mejor construye sino el que más sugiere o especula. Así la arquitectura no es solamente construcción sino acto poético ${ }^{2}$ o de creación, «poiesis». Por lo cual se debe tener clara la raíz etimológica de «poética» que viene del griego poiesis y en su forma verbal poiein (Goya y Muniain en Aristóteles, 2007, p. 49).

Antonio Miranda rescata esta visión aristotélica de la poética para definirla así:

Es, en rigor, la única y verdadera arquitectura, porque renegando de toda fantasía o quimera es causa y efecto de imaginación utópica. Es la verdad formal [...] capaz de conmover la inteligencia. [...] No copia formas sino la razón de las formas. [...] No brilla o deslumbra al gusto de los simios, sino que ilumina la inteligencia de los hombres, ilustra con su transparencia porque contiene el esplendor de la verdad. La arquitectura poética, o arquitectura propiamente dicha, es un artificio más del cosmos, que no imita con obligada torpeza los objetos naturales sino su poética o modo de hacerse. (Miranda, 2008, pp. 114-115).

\section{2. ¿Construir o concebir?}

Étienne Louis Boullée, en su Ensayo sobre arte, nos enseña una serie de proyectos utópicos que rompían con los cánones de la época, replanteando metodológicamente la manera de hacer arquitectura y contraponiéndose al dogmatismo de los tratados. En aquella revolucionaria época de la llustración, Boullée, en su ensayo se desliga de la retórica práctica, y como antítesis vitruviana dijo:
¿Qué es arquitectura? ¿Debería definirla, con Vitruvio, como el arte de construir? No. Esa definición conlleva un error terrible. Vitruvio confunde el efecto con la causa. Hay que concebir para poder obrar. Nuestros primeros padres no construyeron sus cabañas sino después de haber concebido su imagen. Esa creación que constituye la arquitectura es una producción del espíritu por medio de la cual podemos definir el arte de producción y de llevar a la perfección cualquier edificio. El arte de construir no es más que un arte secundario que me parece conveniente definir como la parte científica de la arquitectura. (Boullée, 1985, p. 42).

Es claro que Boullée aboga por concebir antes que construir. Y su más famoso caso podría ser el Cenotafio de Isaac Newton, donde un dibujo resume aquella utopía concebida, que por dicha condición jamás será construida. Sin embargo, ya de por sí es una obra arquitectónica completa. Además, nos ha influido a los arquitectos desde el siglo XVIII. El cenotafio es el rescate de una idea a través del objeto materializado en un dibujo. La idea de rescatar lo sublime de la forma arquetípica.

Lebbeus Woods (2015, p. 8) establece una diferencia entre construcción y arquitectura: "Architecture is something different from building. So what makes it different? The usual answer is: a concept. Architecture is the built realization of a particular concept, or idea." Y a partir de la misma inquietud Raimund diría lo siguiente:

Building or architecture is a polemic involving two realities. Buildings for me means to build with words, lines, shadows, volume and form. Each of these realities is autonomous. It is impossible to assume, however, that architecture can be built, architecture without ideas or a theoretical program being formulated a priori. Architecture is no a profession. Architecture is a project of desire. It is an anticipation of material and construction which finds its expression in a text or a drawing - in a reality, that is, which is different from the one presented by professional architects as the only reality (Abraham, 2011, p. 110)

A diferencia de Woods, Raimund Abraham sí tuvo obra construida. Sin embargo, defiende la idea de la representación de una arquitectura más allá de lo real, no «encasillada» en lo construido, sino que se plantea como ideas y conceptos dibujados. Aquello nos está llevando a la formulación de pensamiento crítico. Cuando hablamos de un proyecto conceptual o teórico, por no decir utópico, estamos hablando de un pretexto que apuntalaría una postura crítica de pensamiento arquitectónico. Así se logra llegar a la crítica propiamente dicha.

Bajo la premisa de ser tanto poéticos como críticos, se entiende que ser poeta es ser creador. Pero la creación no implica producir cosas de la nada. Se crea porque el ser humano tiene la necesidad de manifestarse en el mundo intangible de las ideas, las fantasías, sueños y esperanzas. Busca la razón de las cosas o la verdad detrás de las mismas. Entiéndase esta búsqueda para entender

\footnotetext{
${ }^{1}$ Citado por Andrei Gozak en Ivan Leonidov: The Complete Works. (Gozak y Leonidov, 1988, p. 8).

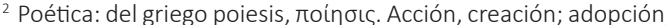
fabricación; composición, y como verbo: hacer, fabricar; engendrar, dar a luz; obtener; causar; crear.
} 
la naturaleza de las cosas como «la imitación» para crear o producir, o desde el punto de vista aristotélico, la «mímesis» ${ }^{3}$ como herramienta de la «poiesis». Si bien ahora se tiene claro qué es crear, ¿cuál sería e paso previo? ¿cómo se hace un preludio a la creación en arquitectura?, ¿cómo surge una idea arquitectónica? Si bien las cosas o acontecimientos no salen de la nada, pueden ser replanteados y evolucionar. Y para esto es necesaria la crítica de lo pretérito. Así, la meta es hacer crítica para repensar o re-conceptualizar el mundo en que vivimos, evolucionándolo para mejorarlo. De tal manera, las ideas saldrán de la crítica. Con ideas se crea, se produce, se concibe. Finalmente, la creación es demostración de la crítica, porque una crítica que no es proyectual o propositiva no es crítica, es solamente «criticonería». Retomando a Miranda, señala lo siguiente: "Una imitación, negadora y dialéctica, que trabaja sobre la crítica y que hace de la evolución y transformación de modelo una "creación» o nuevo nacimiento de mayor verdad. No solamente interpretación sino también crítica neguentrópica. Se trata entonces de la poética" (1999, p. 281).

El ser humano debería promover la elaboración continua de ideas. Aunque sean descabelladas o se fantaseen arquitecturas no rentables e «inútiles» ante los ojos de los promotores. Son ese tipo de arquitecturas las que sobrevivirán como fuente de producción crítica en las futuras generaciones.

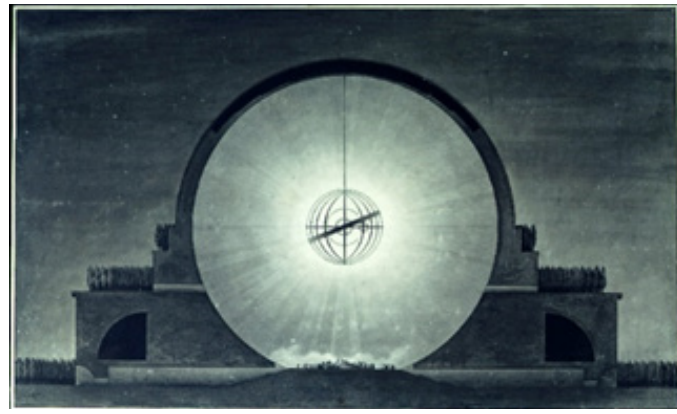

Figura 1: Cenotafio de Isaac Newton ${ }^{4}$ (1784). Proyecto de Étienne Louis Boullée.

Fuente: Imagen de dominio público.

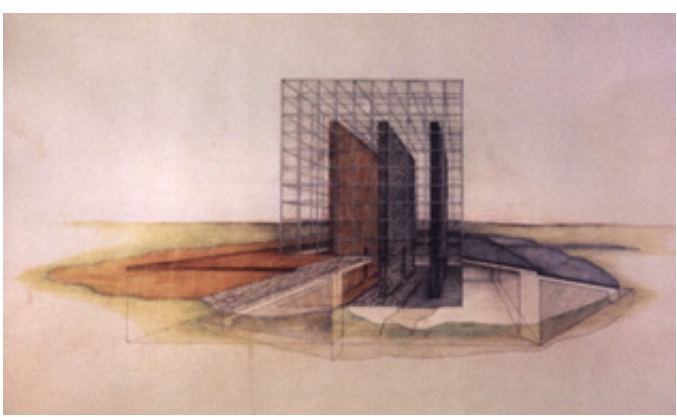

Figura 2: House with three walls (años 70). Proyecto de Raimund Abraham.

Fuente: (Abraham, 2011).

\section{Idea y Utopía: en defensa de una arquitectura imaginada}

Es curioso el significado de la palabra imaginación, y a la vez, todas las palabras citadas anteriormente tienen relación entre sí. Por ejemplo, la palabra griega «idea», que significa "forma o apariencia», y su forma verbal es «eido», que significa ver, y "eidon» significa visión, vista. Así, idea es una representación mental que surge del pensamiento de un ser humano. Desde el punto de vista platónico las ideas son formas o conceptos eternos, es decir arquetípicas. La raíz griega «eidola» significa imagen, y «eidolon», ídolo, relacionado con ícono, viene de «eikon», que a la vez significa modelo (Beardsley y Hospers, 1997, p. 20). Así, la relación de imagen e ideal tiene una connotación «quasi» divina. Giordano Bruno, filósofo malentendido en su tiempo, dijo: "Solo cuando la poesía es verdadera alcanza a la Divina Sabiduría..." (Miranda, 2011, p. 142).

Por otro lado, la raíz latina de imagen, a diferencia de la griega «eidolon», es «imago», que es retrato, imitación o emulación. Imaginación, con su respectivo sufijo, sería «acción y efecto» de representar una imagen o idea en la mente humana (Corominas, 1987, p. 330).

Aquí ya podemos acotar el término «Arquitectura visionaria o imaginaria», la misma que tiene un fin muy claro, que es la producción de pensamiento crítico demostrado a través de objetos arquitectónicos, en este caso, no construidos sino concebidos. A esto se le puede dar el nombre de «método»" el camino más seguro para llegar a un fin. La imaginación como medio para la crítica nos vincula directamente con la «utopía», que bien se puede entender como u-topos, no-lugar, o bien eu-topos, que significa buen lugar. Así, la utopía va más allá de la realidad, la replantea para enseñarnos cómo debe ser.

La realidad es lo que es, y la utopía es la realidad que debe ser, y así llegar a una suprema verdad, una verdad ideal. Son las utopías las que hacen grandes cambios al mundo. Cuando el ser humano se lanza a soñar con lo imposible, como Leonardo, Hipatia, Piranesi, Moro, Verne, Chernikov, Sant'Elia, Boulleé, Galileo, Leonidov, Tesla, Asimov, Platón, Woods, Kepler, Nieuwenhuys, Friedman, entre tantos, inconformes con los límites que nos imponen los sistemas y la realidad, han dado luces al mundo hacia una nueva forma de emprender la vida. El objetivo de la utopía es concebir una nueva realidad que se impone como una crítica a la obsoleta realidad pretérita. Existen

${ }^{3}$ La mímesis o imitación es un medio para la producción poética, no confundir imitación con copia. Mímesis no es lo mismo que mimetismo.

${ }^{4}$ En el ejemplo de la figura 1, Boullée «crea» arquitectura sin inventarse nada. Está imitando o tomando referencia de un arquetipo formal, en este caso, la esfera.

${ }^{5}$ Método, proviene de dos palabras griegas. Meta: más allá. Y Hodos: camino. 
riesgos, obviamente, y enhorabuena. Dichos errores permitirán que se replantee el pensamiento cada vez que sea necesario y así llevar una constante evolución. Evolución que se contrapone al estancamiento, o en el peor de los casos, a una involución: «Distopía».

En la Introducción de una edición reciente de Utopía, Raúl Zoppi dice:

Verdad que es pensada, hecha con ideas, e ideas que piensan. [...] Frente a la circunstancia de una vida sin ética ni justicia Moro se ve obligado a crear una ficción con ideas. ¿Por qué ficción con ideas? Este «con» señala una relación extraña. Relación donde las ideas por medio del relato adquieren existencia real. Esto no significa que las ideas se tornen falsas por la ficción. Las ideas son verdaderas, pero no son la verdad. A la verdad se llega con la realización. A las ideas les falta consumación. Utopía es la narración de las ideas y también la posibilidad de su consumación (Moro, 2003).

En pocas palabras, utopía es una serie de lindas mentiras que nos enseñan grandes verdades. O incluso, que propone nuevas y mejores realidades. Los visionarios que replantean el mundo, el sistema o la zona de confort son «locos». Tan locos que no encajan en una sociedad de «cuerdos». Una «cordura» impuesta por las masas. El buen Cervantes en su Quijote enseña al ser humano a "Vivir loco y morir cuerdo". 6

Hermann Hesse decía: "Quien «no encaja en el mundo», está siempre cerca de encontrarse a sí mismo. Quien encaja en él, no se encontrará nunca, pero llegará a consejero nacional" (Hesse, 2005, p. 40) ¿De qué nos sirven arquitectos con ejercicios lucrativos, si ya no hacen una búsqueda personal para innovar en el oficio y engrandecer el estado de la disciplina? Lamentablemente, en nuestro medio a los arquitectos se nos ha puesto en una celda, por no decir en una camisa de fuerza. La academia hoy en día ya no promueve lanzarnos hacia una propuesta metodológica que nos incite a la utopía. Ni tampoco promueve la materialización y concepción de soluciones arquitectónicas transcendentes para cambiar el mundo. La arquitectura está siendo relegada a una mera profesión que satisface las necesidades de cobijo y lucro. Pero la arquitectura no es solamente eso. Hace casi un siglo, Bruno Taut decía en su obra La Corona de la Ciudad:

Ahora lo que importa es hallar una cierta consonancia que esa interpretación de la arquitectura y del verdadero oficio del arquitecto probablemente sea demasiado restringida. El considerar la arquitectura solo como un modo de satisfacer la utilidad mediante formas bellas, [...] es sin duda una interpretación despreciativa de su importancia. Es precisamente en los edificios que se construyen por algo más que la mera necesidad donde la arquitectura se manifiesta como arte, como un juego de la fantasía que ha perdido casi toda relación con la utilidad. (Taut, 1997, pp. 37-38).

${ }^{6}$ Miguel de Cervantes en El ingenioso hidalgo Don Quijote de la Mancha. La cita textual dice: "Yo fui loco, y ahora soy cuerdo". Cervantes (Quijote II, 74)

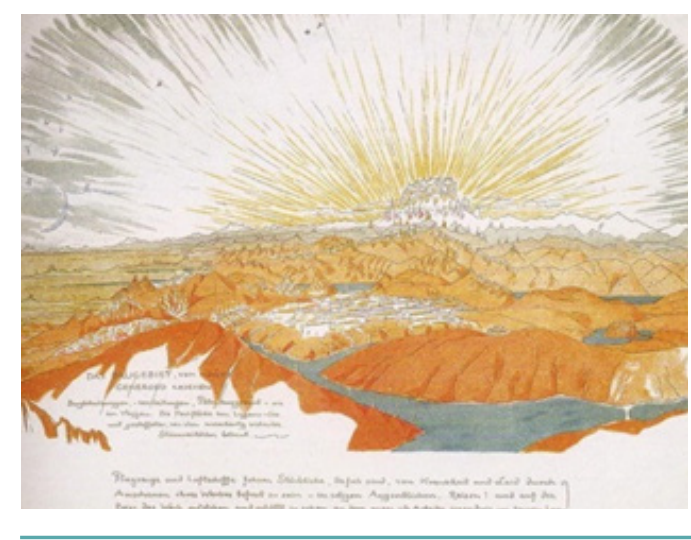

Figura 3: Arquitectura Alpina (1917). Proyecto de Bruno Taut

Fuente: (Taut, 1997).

Las Vanguardias del Movimiento Moderno buscaban reajustar un mundo agitado a través de sus fantasías, contraponiéndose a la ya dogmática visión academicista del siglo XIX. Desde el reformular la forma de vida como los Futuristas Italianos, o imaginar un sistema socioeconómico ideal apuntalado con la arquitectura como los Constructivistas Rusos, hasta los esbozos metodológicos en busca de una educación revolucionaria. Respecto a la primera publicación de lakov Chernikov, la cual fue revolucionaria y polémica para los estándares de su tiempo, dice: "En su filosofía pedagógica, la realidad no era simplemente un resultado: Idealmente, la representación debe mostrar con precisión qué pasa en la imaginación del artista, y la expresión gráfica es mucho más importante que crear la ilusión de la realidad" (Khmelnitsky, 2013, p. 8).

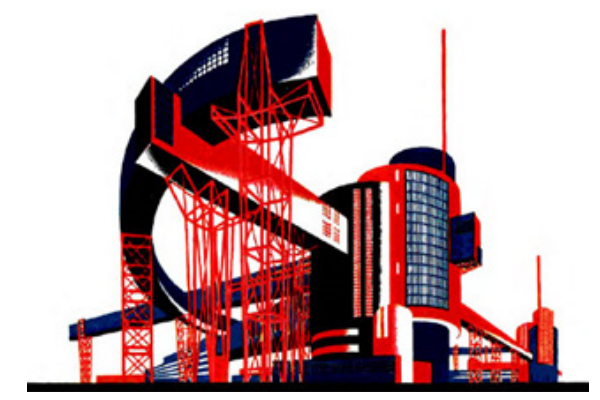

Figura 4: Architectural Fantasies. (1933). Obra de lakov Chernikov.

Fuente: (Cooke, 1984).

Durante la década de los veinte, en la extinta Unión Soviética, se dio una prolífica demostración coyuntural de pensamiento crítico, teórico y pedagógico. Un crisol de creación y especulación sin precedentes. Probablemente se llegó al auge del desarrollo de posturas visionarias, sin comparación alguna con otros períodos de la historia del siglo XX, e incluso, de la historia universal (Jan-Magomédov, 2015, p. 69). Se produjo una amplia divulgación del Constructivismo para lograr llegar al proletariado. La imagen evidentemente fue un buen medio. En la época 
y el medio se defendía una concepción de las artes y los oficios totalmente libres de reminiscencias burguesas, historicistas, sentimentales o románticas. Los constructivistas buscaban una superación del arte negando la preconcepción del mismo. Una forma de pensar totalmente descontaminada, es decir pura. Y como afirmaba Chernikov (1927): "Si de alguna manera podemos transmitir nuestros pensamientos e ideas en forma vaga, sin pretensión de corrección, y si esta imagen refleja nuestra imaginación, entonces podemos tener la conciencia limpia" (Khmelnitsky, 2013, p. 8).

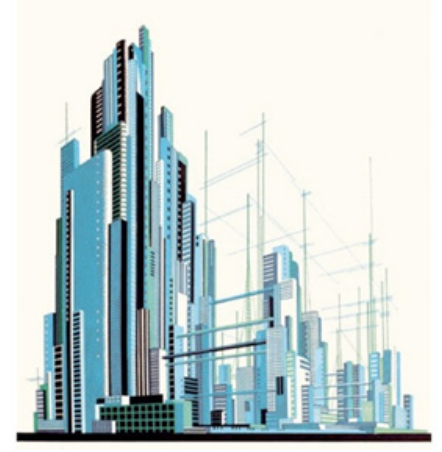

Figura 5: Architectural Fantasies. (1933). Obra de lakov Chernikov.

Fuente: (Cooke, 1984).

Un personaje menos conocido, pero sí importante, fue Georgii Krutikov, un estudiante de los Vjutemás? causó furor en el círculo de arquitectos de vanguardia. En su polémico trabajo de fin de carrera, La Ciudad Voladora, nos planteaba según él mismo: "una ciudad ideal para el sistema económico ideal". (Jan-Magomédov, 2015, p. 85). Su trabajo de licenciatura tenía una componente aeronáutica técnicamente imposible para la época. Sin embargo, el joven Krutikov, no descarta la posibilidad de su factibilidad en el fututo. Respecto a la parte arquitectónica, el proyecto estaba totalmente resuelto. La disertación de su trabajo aclamó muchos comentarios y críticas, tanto a favor como en contra. El periodista Levochski de la revista Postroika escribió: "en los Vjutemas, en lugar de formar a jóvenes constructores bien preparados y eficientes, se dedican a fantasear" (Jan-Magomédov, 2015, p. 65). Incluso el título de dicho artículo era de por sí incisivo: "Los Julios Vernes soviéticos: en los Vjutemás no se forman constructores, sino soñadores. El proyecto de construcción de la ciudad voladora". Respecto a los soñadores, Goya con sus Disparates o Brueghel con El triunfo de la muerte, soñaron alguna vez, y así cambiaron la forma de ver el arte. Aquella especulación para replantear el mundo y romper con lo preestablecido ha sido lo que permite una constante evolución del estado del arte.

Jan-Magomédov, alabando la especulación creativa de la vanguardia soviética dijo:

${ }^{7}$ Talleres de Enseñanza Superior del Arte y de la Técnica. Escuela estatal fundada en Moscú por decreto de Lenin en 1920.
En estos años se concibieron proyectos que no solo podían parecer un completo rechazo a la tradición, sino que además no eran nada realistas. Los experimentos innovadores destruían las viejas concepciones y superaban los estereotipos establecidos. Muchos proyectos de la época ejercieron gran influencia en el devenir de la arquitectura del siglo XX y significaron importantes descubrimientos creativos. Pasados los años, los proyectos que entonces parecían fantasiosos, ahora se perciben como algo perfectamente realizables. (Jan-Magomédov, 2015, p. 69).

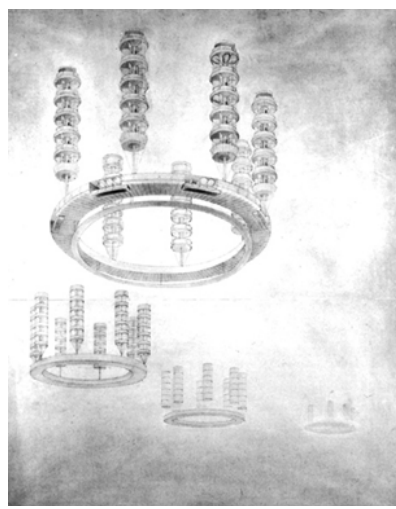

Figura 6: Ciudad Voladora. (1928). Proyecto de fin de carrera de Georgii Krutikov.

Fuente: (Jan-Magomédov, 2015).

\section{Meta-hodos «Método»: El dibujo como medio de materialización}

Louis Kahn defendía que un buen dibujo "encarna las posibilidades ocultas de su oficio; son las auténticas visiones de un creador" (Kahn, 2003, p. 16) y por tal razón sostiene que la importancia no radica en la precisión de la representación, sino es su propósito. El propósito de un Louis Kahn defendía que un buen dibujo "encarna las posibilidades ocultas de su oficio; son las auténticas visiones de un creador" (Kahn, 2003, p. 16) y por tal razón sostiene que la importancia no radica en la precisión de la representación, sino es su propósito. El propósito de un boceto, por más escueto que sea, debe decir ambicioso. Es el caso de Erich Mendelsohn o de Hans Scharoun que con muy pocos trazos logran transmitir sus posturas de diseño, concepción formal, espacial y tectónica. Así el boceto se convierte en una importante herramienta de génesis arquitectónica y a la vez en una pieza pictórica. Nos podríamos atrever a opinar que los bocetos de Scharoun son más sugerentes que sus obras tempranas construidas, incluso que a partir de estos bocetos, empezó a madurar un pensamiento que se llevaría a cabo un par de décadas después cuando materializa la Filarmónica de Berlín. Antes de determinar conclusiones, podríamos

${ }^{8}$ Se entiende como neo-vanguardias para diferenciarse de las vanguardias de principios de siglo XX que fundamentaron al Movimiento Moderno. 
plantear una hipótesis y preguntarnos chubiera sido posible la Filarmónica sin sus especulaciones gráficas años atrás? El dibujo es el medio que permite lanzarnos hacia una fantasía ideada por algún arquitecto. En la Disolución de las Ciudades, Taut nos plantea ¿es posible dibujar la felicidad? Todos nosotros la podemos experimentar y construir" (Taut, 1997, p. 297). No es necesario que aquella utopía se construya con piedras, granito, acero o ladrillo. Se puede construir en el papel. Y tendrá su influencia a posteriori. Como sucedería en los años sesenta con las neo-vanguardias ${ }^{8}$ de Archigram muy propositivas, pero esta vez desde una perspectiva pop. Las fantasías de Archigram, más que ciudades imposibles eran los planteamientos de nuevas formas de ver la vida cotidiana y además una crítica al estado de la arquitectura.

Refiriéndose al trabajo en Archigram, Peter Cook diría:

Es significativo que con este material existe un puente de inspiración, que se extiende a los cuarenta años en el pasado y quizás cuarenta años en el futuro, y tal vez la respuesta no se encuentra ni en lo heroico ni en lo trágico, sino en un resurgimiento del valor de las convicciones en la arquitectura (Cook, 1999, p. 29. Trad. del autor).

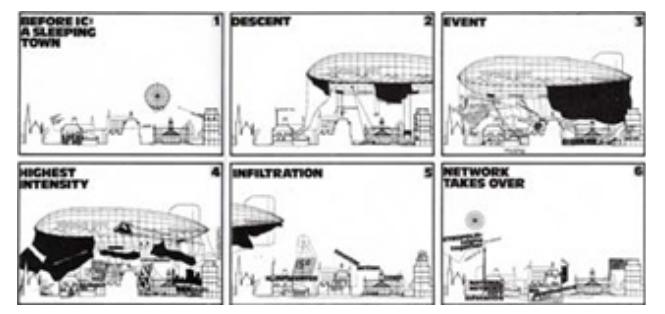

Figura 7: Instant City. (Años 60). Proyecto de Archigram. Fuente: (Cook, 1999).

Peter Cook en este texto defiende una reivindicación de la esencia de la arquitectura. Y siglos atrás veríamos lo mismo a través de la imaginación de Giovann Battista Piranesi, célebre grabador italiano del siglo XVIII. Indagó en una búsqueda de complejidad espacial en la arquitectura con su serie de grabados Carceri $d^{\prime}$ invenzione o Prisiones Imaginarias. Este trabajo influiría tanto en el Romanticismo como en el Surrealismo. Lo más importante fue la ruptura de la visión centralizada del espacio. A diferencia de las imágenes del Renacimiento, la percepción del espacio se la brindaba a través de un único punto de fuga, mientras que en Piranesi, sus cárceles nos invitan a «perdernos» en ellas. La imaginación de espacios complejos e incluso el planteamiento de un laberinto visual. El que visualiza una cárcel de Piranesi a través de un grabado, no está siendo partícipe de la impresión solamente, sino que además es partícipe de una experiencia arquitectónica sin necesidad de un espacio "construido». Basta ser concebido para «habitarlo». Ficcaci dice "Los grabados de Piranes «mostraron» realidades de manera inimaginable y sin precedentes. Independientes del tema, siempre revelan algo nuevo. Podrían ser creaciones arquitectónicas modernas, caprichos de la imaginación” (Ficacci, 1999, p. 27).

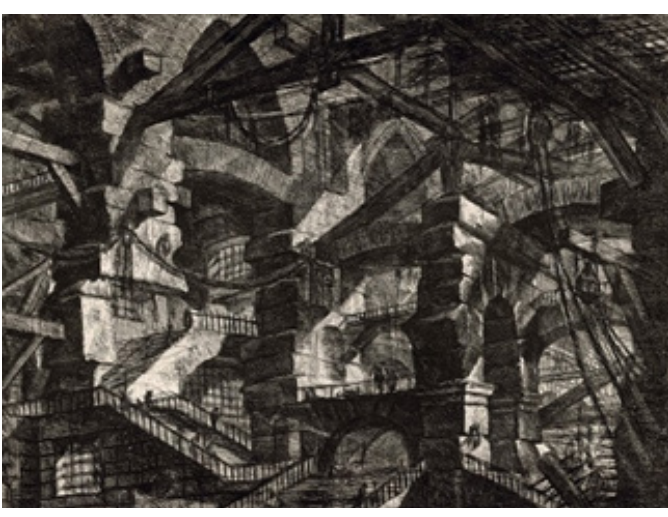

Figura 8: Carceri d'invenzione. (1750). Grabados de Giovanni Batista Piranesi.

Fuente: (Ficacci, 1999).

La influencia de Boullée, y su rescate de la pureza formal, marcaría tanto en arquitectos modernos como Le Corbusier o Ivan Leonidov. Este último, otro exponente del Constructivismo Ruso, además de ser un comunista convencido, también utilizó la imaginación para plantear soluciones utópicas para lo que "parecería» que iba a ser aquella nueva forma de gobierno político en la Unión Soviética. Es muy célebre su trabajo de licenciatura, el Instituto Lenin, que nos enseña una nueva visión en la manera de diseñar bibliotecas. El proyecto es producto de una abstracción de formas puras, incluso sus planimetrías parecerían auténticas obras supremacistas. Es evidente la influencia de Malevich y Kandinsky en Leonidov. El proceso creativo de los arquitectos del Movimiento Moderno, a pesar de la relación con otras artes, no es representacional, sino más bien el manejo de la forma por derecho propio y, por tanto, un homenaje a la abstracción (Khmelnitsky, 2013, p. 10).

A esto podemos citar a Chernikov (1930) que como teórico dijo:

La construcción abstracta no impone restricciones a nuestros estudiantes, sino que los libera de métodos conservadores anticuados y les permite dar rienda suelta a su imaginación (Khmelnitsky, 2013, p. 10)

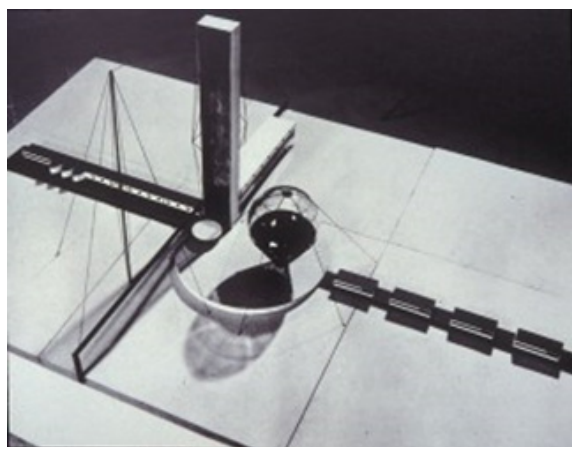

Figura 9: Instituto Lenin. (1927). Proyecto de fin de carrera de Ivan Leonidov,

Fuente: (Gozak y Leonidov, 1988). 
Es claro que Leonidov, Chernikov y tantos otros arquitectos constructivistas hicieron un acto poético sin límites impuestos, y solamente así llegaron a cumplir metas. Esos objetivos no serían para la arquitectura solamente, sino para el conocimiento, civilización, humanidad y sociedad. El dibujo más que una ilusión de un futuro utópico anhelado era un punto de partida para la definición de proyectos arquitectónicos «reales».

Khmelnitsky comenta sobre las Architectural Fantasies:

Al igual que muchos otros conceptos, la palabra «fantasía» en el título tiene un significado muy especial para Chernikhov, refiriéndose no a las utopías arquitectónicas o a las representaciones de fantasías arquitectónicas pasadas o futuras, sino a dibujos de trabajo específicos utilizados para desarrollar ideas para un proyecto real. En la introducción, Chernikhov explica que la "fantasía arquitectónica» es el primer paso en cada proceso de diseño: todos los arquitectos deben comenzar dando rienda suelta a su imaginación y luego conservando los resultados inconclusos de esta creatividad (Khmelnitsky, 2013, p. 17-18)

El dibujo de utopías arquitectónicas también son un medio para representar "discursos arquitectónicos» o bien, posturas de diseño gráficas. Las Imágenes de la Città Nuova de Antonio Sant'Elia, nos dan una lectura muy clara de los ideales del Futurismo. A través de dibujo nos demuestra la capacidad de monumentalizar nuestros nuevos templos; la fábrica, la central eléctrica o la estación de tren. Es tan sugestiva la imagen que los dibujos pueden transmitir el pensamiento de un arquitecto incluso sin leer sus manifiestos.

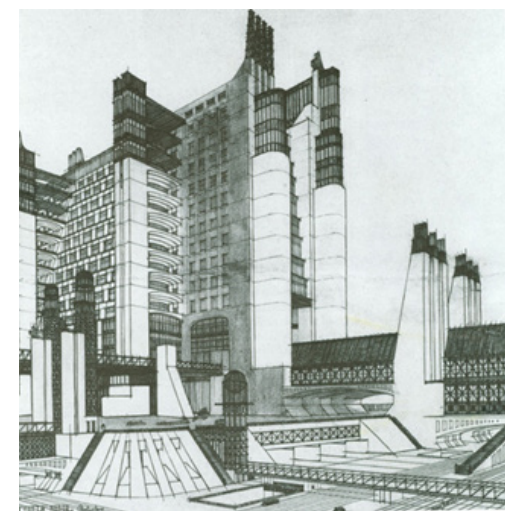

Figura 10: Città Nuova. (1914). Imagen de Antonio Sant'Elia.

Fuente: Dominio público.

Con similitud, pero diferente temática es el caso de Lebbeus Woods. En el prólogo de Radical Reconstruction, Aleksandra Wagner dice: "Lo que se propone es que la arquitectura, en sí misma encarne el conocimiento, reconozca la sustancia que la hace posible - posible, no aparente; Pensado y dibujado, no construido." (Woods, 2001, p. 9). Prominente en el campo de la arquitectura conceptual o experimental, Woods nunca construyó ningún proyecto. Sin embargo, su producción gráfica es prolífica. Es importante mencionar algunos de sus trabajos como; Radical Reconstruction, Havana Walls o War and Architecture. Estos trabajos son posturas 0 manifiestos dibujados. No nos enseñan proyectos, sino formas de afrontar problemáticas a través de posturas de reflexión arquitectónica. En War and Architecture (1993) por ejemplo, la postura de afrontar reconstrucciones posbélicas, recuperando el acontecimiento como herramienta para el desarrollo del proyecto, sin negar la historia. Nos muestra cómo la destrucción o huellas de guerra nos dan pautas para hacer arquitectura dialéctica que a la vez sea un homenaje a las víctimas del acontecimiento bélico. Este manifiesto lo hizo específicamente para Sarajevo justo después de la Guerra de los Balcanes.

Aunque Woods $(2015$, p. 7) dice que la arquitectura no se desarrolla necesariamente en un entorno construido, y la razón es obvia; el arquitecto no es quien decide si se construye o no. Obviamente, eso depende de los inversores comerciales, clientes, usuarios, comunidades, «modas», etc. En el siglo XVIII, Boullée nos planteó la siguiente pregunta: “¿Diríamos entonces que es conveniente que el arquitecto abandone negocios lucrativos para seguir estudios de pura especulación? ¡Ay! ¿Quién es aquel que haría gustosamente el sacrificio de la fortuna o, incluso, de lo necesario cuando se le presenta?" (Boullée, 1985, p. 46). La respuesta es sí. Un rotundo sí. Y el que lo haría gustosamente «debería ser» el arquitecto. Arquitecto en el estricto sentido de la palabra.

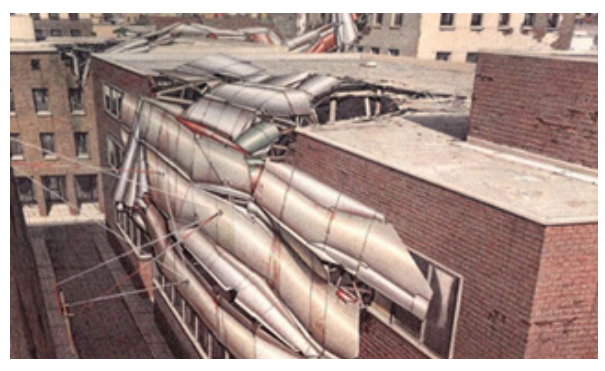

Figura 11: War and Architecture (1993). Obra de Lebbeus Woods

Fuente: (Woods, 1993)

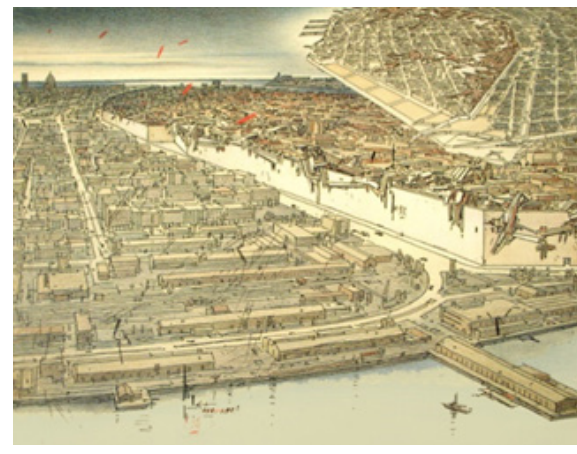

Figura 12: Havana Walls, Habana La Vieja (1994). Proyecto de Lebbeus Woods.

Fuente: (Woods, Radical Reconstruction, 2001). 


\section{Conclusiones}

Mediante esta reflexión, se ha defendido una metodología en la cual la especulación teórica llega a ser un medio para formular nuevas posturas críticas de la arquitectura. El pensamiento se materializa a través de la ideación gráfica. Así, el dibujo es la herramienta fundamental para concebir arquitectura y a la vez transmitirla a los demás. Muchas de estas obras arquitectónicas serán construidas, algunas no. Sin embargo, como se ha visto en los casos citados, la construcción física no es condición para una arquitectura realizada, es decir concebida. Se debería fomentar este tipo de metodología ya que el único límite es la imaginación humana, así se abriría el debate académico y profesional. Más enriquecedoras son las posturas que plantean más preguntas que respuestas. De esta manera, la polémica generada por la utopía obligará a indagar en soluciones trascedentes en el campo de la arquitectura. Defendiendo esta postura, se ha tomado la libertad de hacer algunos «divertimentos arquitectónicos», tanto en la docencia como en la vida profesional. Se puede decir que las experimentaciones especulativas promueven la formación personal de un pensamiento crítico y teórico.

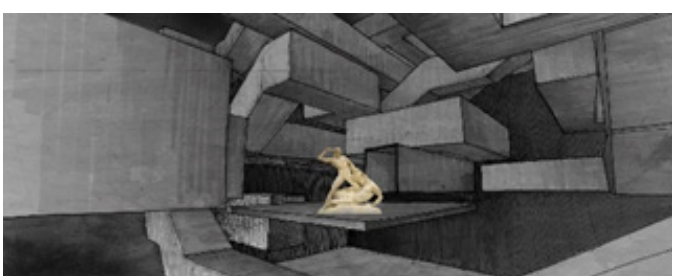

Figura 13: Laberinto del Minotauro. (2015). Proyecto utópico de Javier Eduardo Benavides.

Fuente: Dibujo del autor. 


\section{Referencias bibliográficas}

- Abraham, R. (2011). [Un]Built (2a ed.). Viena, Austria: Springer.

- Aristóteles. (2007). Arte Poética (4ta ed.). México DF México: Porrúa.

- Beardsley, M., y Hospers, J. (1997). Estética: historia y fundamentos. Madrid, España: Cátedra.

- Benavides, J. (2015). Laberinto del Minotauro. Quito, Ecuador: Archivo personal.

- Boullée, E. L. (1985). Arquitectura: Ensayo sobre el arte. (C. Sambricio, Ed.) Barcelona, España:Gustavo Gili.

- Chernikov, I. (1927). Iskustvo nachertaniya. Leningrado. (pp. 21-22). En Khmelnitsky, D. (2013). Yakov Chernikhov: Architectural Fantasies in Russian Constructivism (p. 8). Berlín, Alemania: DOM Publishers.

- Chernikov, I. (1930). Osnovy sovremenoi arkhitektury. Leningrado. (p. 16). En Khmelnitsky, D. (2013). Yakov Chernikhov: Architectural Fantasies in Russian Constructivism (p. 10). Berlín, Alemania: DOM Publishers.

- Cook, P. (1999). Archigram. Nueva York, Estados Unidos: Princeton Architectural Press.

- Cooke, C. (1984). Fantasy and Construction: lakov Chernikhov's Approach to Architectural Design. Londres, Reino Unido: Architectural Design.

- Corominas, J. (1987). Breve Diccionario Etimológico de la Lengua Castellana. Madrid, España: Gredos.

- Ficacci, L. (1999). Giovanni Batista Piranesi: the Complete Etchings. Los Ángeles, Estados Unidos: Klotz Series. Taschen America, LLC.

- Gozak, A., y Leonidov, A. (1988). Ivan Leonidov: The Complete Works. Nueva York, Estados Unidos: Rizzoli.
- Hesse, H. (2005). Lecturas para minutos 1. (A. S. Pobes, y M. Olasagasti Gaztelumendi, Trads.) Madrid, España: Alianza.

- Jan-Magomédov, S. O. (2015). Gueorgui Krútikov. Kahn, L. (2003). Escritos, conferencias y entrevistas. (A. Latour, Ed.) Madrid, España: El Croquis.

- Khmelnitsky, D. (2013). Yakov Chernikhov: Architectura Fantasies in Russian Constructivism (Primera ed.). Berlín, Alemania: DOM Publishers.

- Miranda, A. (1999). Ni robot ni bufón. Madrid, España: Ediciones Cátedra.

- Miranda, A. (2008). Columnas para la resistencia Madrid, España: Mairea Libros.

- Miranda, A. (2011). A todos los becarios de la reina: ocho ensayos de estética civil. Madrid, España: Biblioteca Nueva.

- Moro, T. (2003). Utopía. (R. Zoppi, Ed.) Buenos Aires, Argentina: Losada.

- Taut, B. (1997). Escritos Expresionistas. Escritos, 1919 1920. (I. Ábalos, Ed., y M. D. Ábalos, Trad.) Madrid, España: El Croquis.

- Woods, L. (1993). War and Architecture. Pamphlet Architecture 15. Nueva York, Estados Unidos: Princeton Architectural Press.

- Woods, L. (2001). Radical Reconstruction. Nueva York, Estados Unidos: Princeton Architectural Press.

- Woods, L. (2015). Slow Manifesto: Lebbeus Woods Blog (C. Jacobson, Ed.) Nueva York, Estados Unidos: Princeton Architectural Press. 